\title{
SPATIAL VARIABILITY OF INDOOR RADON CONCENTRATION IN SCHOOLS: IMPLICATIONS ON RADON MEASUREMENT PROTOCOLS
}

\author{
Z. Curguz ${ }^{1}$, G. Venoso ${ }^{2}$,, Z S. Zunic ${ }^{3}$, D. Mirjanic ${ }^{4}$, M. Ampollini ${ }^{2}$, C. Carpentieri ${ }^{2}$, C. Di Carlo ${ }^{2}$, \\ M. Caprio ${ }^{2}$, D. Alavantic ${ }^{3}$, P. Kolarz ${ }^{5}$, Z. Stojanovska ${ }^{6}$, S. Antignani ${ }^{2}$ and F. Bochicchio ${ }^{2}$ \\ ${ }^{1}$ Faculty of Transport, University of East Sarajevo, Doboj, Republic of Srpska \\ ${ }^{2}$ Italian National Institute of Health, National Center for Radiation Protection and Computational Physics, \\ Viale Regina Elena, 299-00161 Rome, Italy \\ ${ }^{3}$ Vinca Institute of Nuclear Sciences, Department of Radiobiology and Molecular Genetics, University of \\ Belgrade, P.O. Box 522, 11000 Belgrade, Serbia \\ ${ }^{4}$ Academy of Sciences and Arts of Republic of Srpska, Banja Luka, Republic of Srpska \\ ${ }^{5}$ Institute of Physics Belgrade, University of Belgrade, Belgrade, Serbia \\ ${ }^{6}$ Faculty of Medical Sciences, Goce Delcev University, 2000 Stip, Republic of North Macedonia \\ *Corresponding author: gennaro.venoso@iss.it
}

\begin{abstract}
The requirements about radon measurements in schools and public buildings included in most of the national and international legislations are generally restricted to all the rooms located at the ground floor and basement, assuming the soil beneath the building as the main source of indoor radon. In order to verify such an assumption for small buildings having at maximum two floors, a preliminary study was performed in $\mathbf{5 0}$ schools located in 15 municipalities of the Republic of Srpska. Results of this study suggest that a protocol requiring measurements at the ground floor only may be considered adequate. Due to the high radon spatial variability for rooms at the ground floor, it is preferable to require measurements in a high number of rooms (preferably in all of them) in order to assess the compliance with the reference level established by the legislation.
\end{abstract}

\section{INTRODUCTION}

The new requirements included in the recommendations and regulations of international organizations will certainly increase the number of radon concentration measurements in workplaces. ${ }^{(1-2)}$ Protocols used for workplaces (including schools) are generally different from those used for dwellings, mostly due to fact that radon spatial variability in workplaces is higher than in dwellings. ${ }^{(3)}$ For dwellings, it is generally recommended to measure the most inhabited rooms ${ }^{(4-5)}$; for workplaces, rooms to be measured are generally more numerous.

According to the 2013/59/Euratom Directive, some protocols give priority to measurements in workplaces and schools located in certain areas (i.e. radon priority areas). Assuming that the soil beneath the building is the main source of indoor radon, some protocols recommend to measure all the occupied rooms located at the ground floor and basement only. ${ }^{(6)}$ Assuming so, it means that measuring radon concentrations in rooms located at the floors in contact with ground allows to fulfill the compliance with reference level (RL) established by national legislations. ${ }^{(7)}$

For multistory buildings, some of these protocols require measurements to be performed also at upper floors, but only if at the ground floor (or basement), the radon levels resulted to be higher than the RL. ${ }^{(6)}$ Measurements at upper floors are generally recommended in case of a possible stack effect from stairwells and/or any ducts such as those for air-conditioning and elevators. ${ }^{(7)}$

In the framework of an extensive survey in schools conducted in Republic of Srpska (Federation of Bosnia and Herzegovina), a preliminary study on the spatial variability of radon concentration in small buildings (having at maximum two floors) was performed. The aim of this study was to obtain information useful for the optimization of the measurement protocol in this type of building.

\section{MATERIALS AND METHODS}

\section{Sample characteristics}

Radon concentration measurements were performed in 50 schools: 33 of them have two floors (ground and first floors); the remaining 17 have ground floor only. The buildings are located in 15 municipalities. In each municipality, the number of surveyed buildings ranges between 1 and 25 (in Banja Luka, the main city of Republic Srpska) with a median number equal to 4 . 


\title{
SPATIAL VARIABILITY OF INDOOR RADON CONCENTRATION IN SCHOOLS: IMPLICATIONS ON RADON MEASUREMENT PROTOCOLS
}

\author{
Z. Curguz ${ }^{1}$, G. Venoso ${ }^{2}$,, Z S. Zunic ${ }^{3}$, D. Mirjanic ${ }^{4}$, M. Ampollini ${ }^{2}$, C. Carpentieri ${ }^{2}$, C. Di Carlo ${ }^{2}$, \\ M. Caprio ${ }^{2}$, D. Alavantic ${ }^{3}$, P. Kolarz ${ }^{5}$, Z. Stojanovska ${ }^{6}$, S. Antignani ${ }^{2}$ and F. Bochicchio ${ }^{2}$ \\ ${ }^{1}$ Faculty of Transport, University of East Sarajevo, Doboj, Republic of Srpska \\ ${ }^{2}$ Italian National Institute of Health, National Center for Radiation Protection and Computational Physics, \\ Viale Regina Elena, 299-00161 Rome, Italy \\ ${ }^{3}$ Vinca Institute of Nuclear Sciences, Department of Radiobiology and Molecular Genetics, University of \\ Belgrade, P.O. Box 522, 11000 Belgrade, Serbia \\ ${ }^{4}$ Academy of Sciences and Arts of Republic of Srpska, Banja Luka, Republic of Srpska \\ ${ }^{5}$ Institute of Physics Belgrade, University of Belgrade, Belgrade, Serbia \\ ${ }^{6}$ Faculty of Medical Sciences, Goce Delcev University, 2000 Stip, Republic of North Macedonia \\ *Corresponding author: gennaro.venoso@iss.it
}

\begin{abstract}
The requirements about radon measurements in schools and public buildings included in most of the national and international legislations are generally restricted to all the rooms located at the ground floor and basement, assuming the soil beneath the building as the main source of indoor radon. In order to verify such an assumption for small buildings having at maximum two floors, a preliminary study was performed in $\mathbf{5 0}$ schools located in 15 municipalities of the Republic of Srpska. Results of this study suggest that a protocol requiring measurements at the ground floor only may be considered adequate. Due to the high radon spatial variability for rooms at the ground floor, it is preferable to require measurements in a high number of rooms (preferably in all of them) in order to assess the compliance with the reference level established by the legislation.
\end{abstract}

\section{INTRODUCTION}

The new requirements included in the recommendations and regulations of international organizations will certainly increase the number of radon concentration measurements in workplaces. ${ }^{(1-2)}$ Protocols used for workplaces (including schools) are generally different from those used for dwellings, mostly due to fact that radon spatial variability in workplaces is higher than in dwellings. ${ }^{(3)}$ For dwellings, it is generally recommended to measure the most inhabited rooms ${ }^{(4-5)}$; for workplaces, rooms to be measured are generally more numerous.

According to the 2013/59/Euratom Directive, some protocols give priority to measurements in workplaces and schools located in certain areas (i.e. radon priority areas). Assuming that the soil beneath the building is the main source of indoor radon, some protocols recommend to measure all the occupied rooms located at the ground floor and basement only. ${ }^{(6)}$ Assuming so, it means that measuring radon concentrations in rooms located at the floors in contact with ground allows to fulfill the compliance with reference level (RL) established by national legislations. ${ }^{(7)}$

For multistory buildings, some of these protocols require measurements to be performed also at upper floors, but only if at the ground floor (or basement), the radon levels resulted to be higher than the RL. ${ }^{(6)}$ Measurements at upper floors are generally recommended in case of a possible stack effect from stairwells and/or any ducts such as those for air-conditioning and elevators. ${ }^{(7)}$

In the framework of an extensive survey in schools conducted in Republic of Srpska (Federation of Bosnia and Herzegovina), a preliminary study on the spatial variability of radon concentration in small buildings (having at maximum two floors) was performed. The aim of this study was to obtain information useful for the optimization of the measurement protocol in this type of building.

\section{MATERIALS AND METHODS}

\section{Sample characteristics}

Radon concentration measurements were performed in 50 schools: 33 of them have two floors (ground and first floors); the remaining 17 have ground floor only. The buildings are located in 15 municipalities. In each municipality, the number of surveyed buildings ranges between 1 and 25 (in Banja Luka, the main city of Republic Srpska) with a median number equal to 4 . 


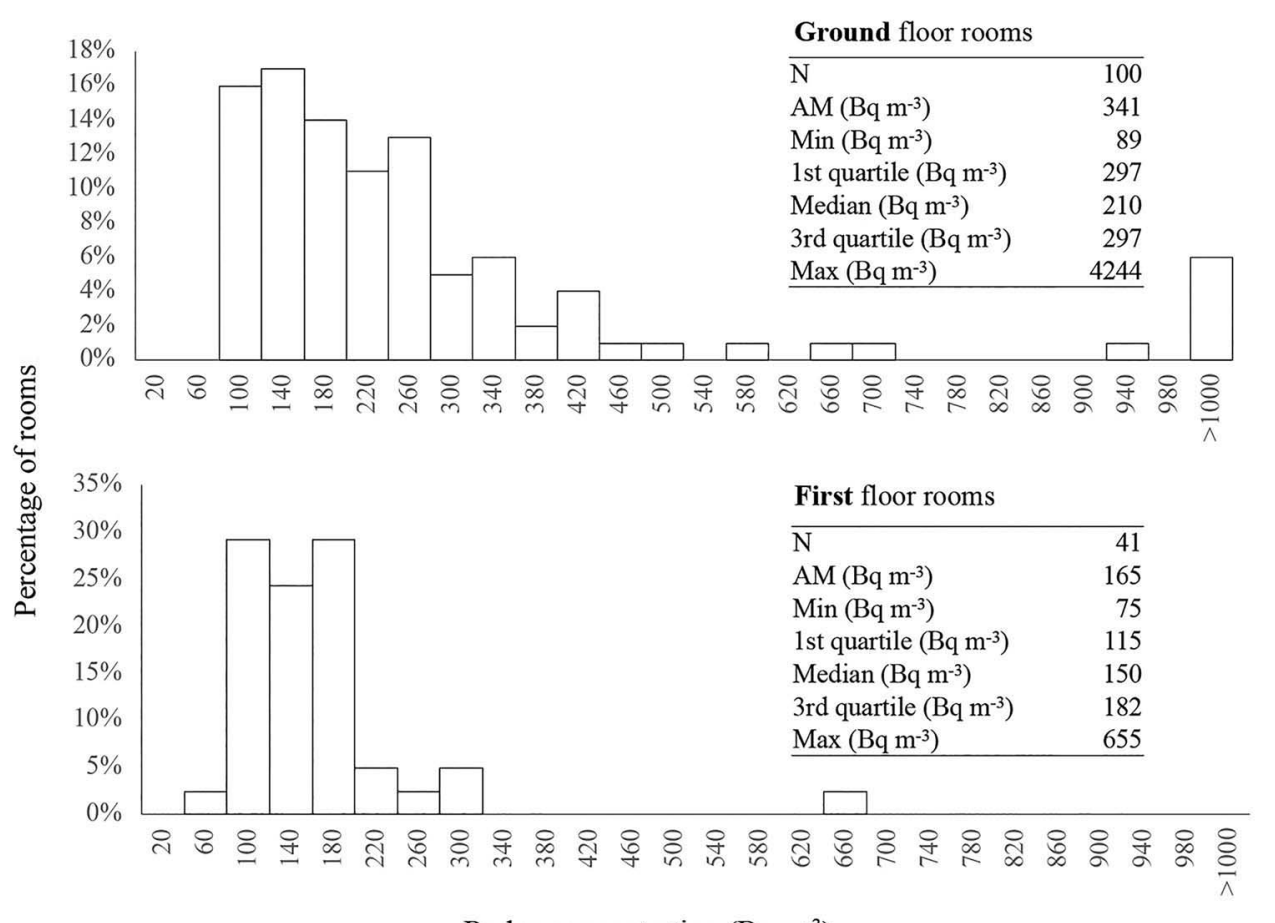

Radon concentration $\left(\mathrm{Bq} \mathrm{m}^{-3}\right)$

Figure 1: Radon concentration distribution for ground floor rooms (top) and first floor rooms (bottom).

\section{Sampling protocol}

A total of 141 rooms were measured. Taking into account the resources and the aim of the survey, a sampling protocol that requires at least two radon detectors for each building was adopted. For buildings having two floors, at least one detector for each floor was deployed. Radon measurements were carried out only in rooms occupied by pupils and staff of the schools, i.e. classrooms and laboratories. However, since all the laboratories are used as classrooms, all the monitored rooms are always occupied during the working hours, and they have approximately the same ventilation regime.

\section{Radon measuring system}

Radon measurements were performed using devices based on CR-39 detectors (manufactured by IntercastEurope srl) enclosed in conductive holders (mi.amradout type). The etching took place in a thermal bath containing a $6.25 \mathrm{M} \mathrm{NaOH}$ solution at $98^{\circ} \mathrm{C}$ for $60 \mathrm{~min}$. Track counting was carried out with a fully automatic image analysis readout system (Politrack). It was chosen a single exposure period of about 1 year considering that these CR-39 detectors (and their measurement techniques) do not show an appreciable sensitivity decrease due to ageing and fading effects. ${ }^{(8)}$

\section{RESULTS AND DISCUSSION}

\section{Radon concentration distributions}

For all the monitored rooms, radon concentration distributions in the rooms located at the ground floor and first floor are separately represented in Figure 1.

Radon concentrations at the ground floor are generally higher than at first floor: indeed, they range from about 90 to about $4200 \mathrm{~Bq} \mathrm{~m}^{-3}$, and for more than $25 \%$ of these rooms, radon concentrations are higher than $300 \mathrm{~Bq} \mathrm{~m}^{-3}$, the maximum reference level for workplaces established by the 2013/59/Euratom Council Directive. $^{(1)}$

However, as regard to the rooms at first floor, even if the radon concentration was on average lower than that at the ground floor, radon levels were higher than $300 \mathrm{~Bq} \mathrm{~m}^{-3}$ in about $\%$ of the surveyed rooms.

The impact of floor level on radon concentration is well known due to fact that generally the main entry route for radon indoor is the soil beneath the buildings, ${ }^{(9)}$ and it was confirmed by several data analyses being conducted in the framework of surveys in dwellings (e.g. $\left.{ }^{(10,11)}\right)$ as well as in schools located in the same area. ${ }^{(12)}$ For a subsample of 33 buildings, described in the next paragraph, the dependence of the average radon concentration on floor levels was also estimated using data of the present work. 


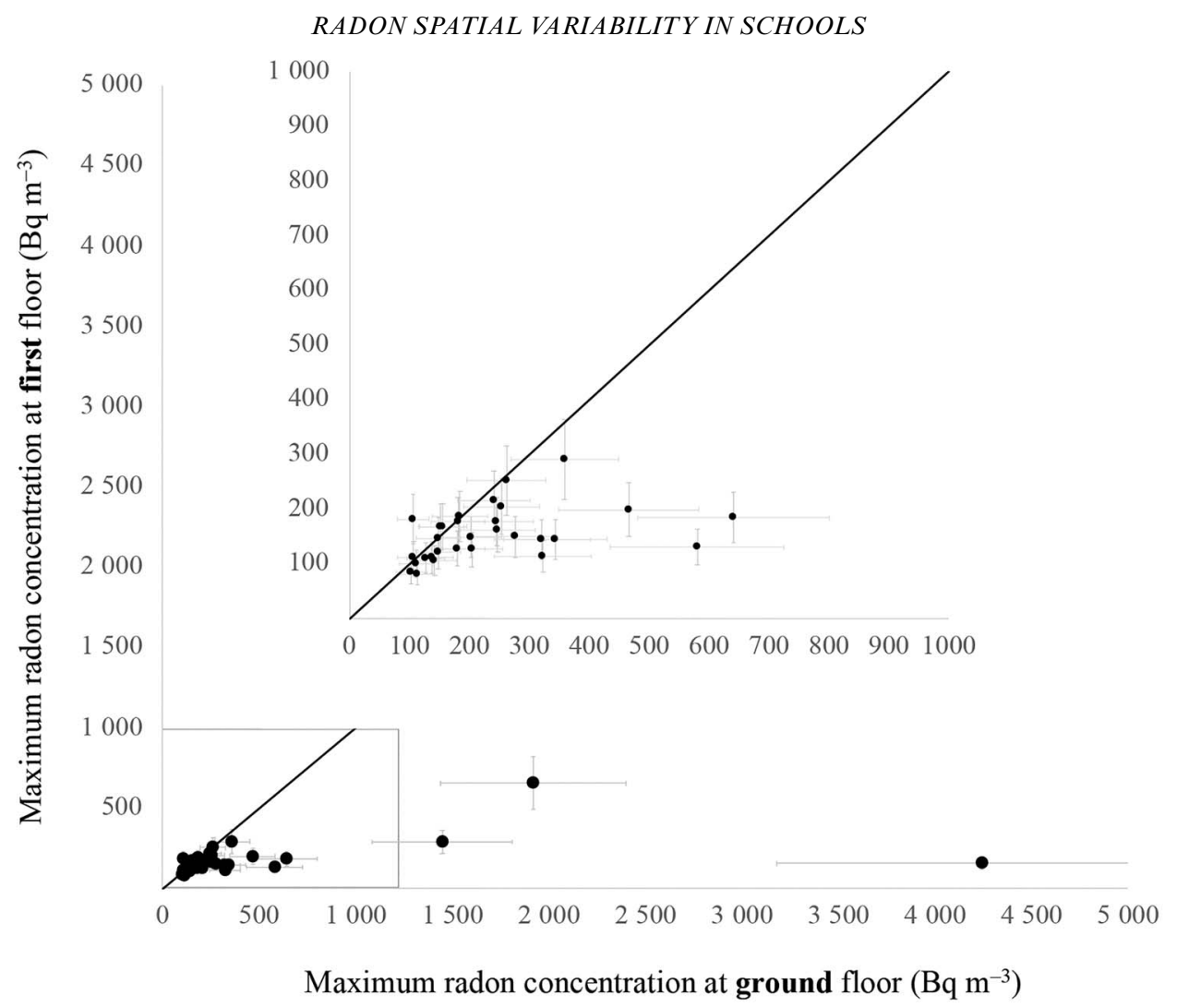

Figure 2: Maximum radon level at ground floor versus that at first floor. The reported uncertainties have a coverage factor $k=2$. The line represents the bisecting line. The region between 0 and $1000 \mathrm{~Bq} \mathrm{~m}^{-3}$ was zoomed and reported in the box above.

\section{Radon level versus floor level}

For each of the 33 buildings having radon concentration measurements both in the rooms at the ground floor and at the first floor, the maximum radon level was calculated for each floor (Figure 2).

As expected, for the same building, radon levels were generally higher at the ground floor than at the first floor. Notably, if rooms with radon levels higher than $300 \mathrm{~Bq} \mathrm{~m}^{-3}$ (or higher than $200 \mathrm{~Bq} \mathrm{~m}^{-3}$ ) were found at first floor, they were also found at ground floors. On the contrary, for buildings with the radon concentrations exceeding $300 \mathrm{~Bq} \mathrm{~m}^{-3}$ at the ground floor rooms, this concentration level was exceeded only in 1 of 10 cases at the first floor. If confirmed by further studies, this result suggests that it may be sufficient to perform measurement only in rooms located at the ground floor when verifying the compliance with reference levels for all buildings rooms. In other words, if no exceedance of RL was found in a significant number of rooms monitored at ground floor, it is very unlikely to find radon level exceeding $\mathrm{RL}$ at higher floors.
Moreover, it is worth noting that in case of radon surveys aimed to evaluate radon exposure of the pupils and staff of schools, it is necessary to know radon levels at every occupied floor of the buildings. Therefore, protocols used for these surveys have to include also measurements at higher floors. The number of rooms which is preferable to measure at different floors depends on the spatial variability of radon concentration at each floor.

\section{Room-to-room spatial variability}

For each building, radon spatial variability has been estimated as the coefficient of variation $(\mathrm{CV})$ of radon concentration between rooms (room-to-room variability), separately for the ground and first floor rooms (Figure 3). For rooms at the ground floor, spatial variability has been estimated in 36 buildings. In 22 of them, radon levels were measured in 2 rooms; in the remaining 14 buildings, in 3 rooms. For rooms at first floor, this kind of variability was estimated in eight buildings, in each of them, measuring was done at two rooms. 


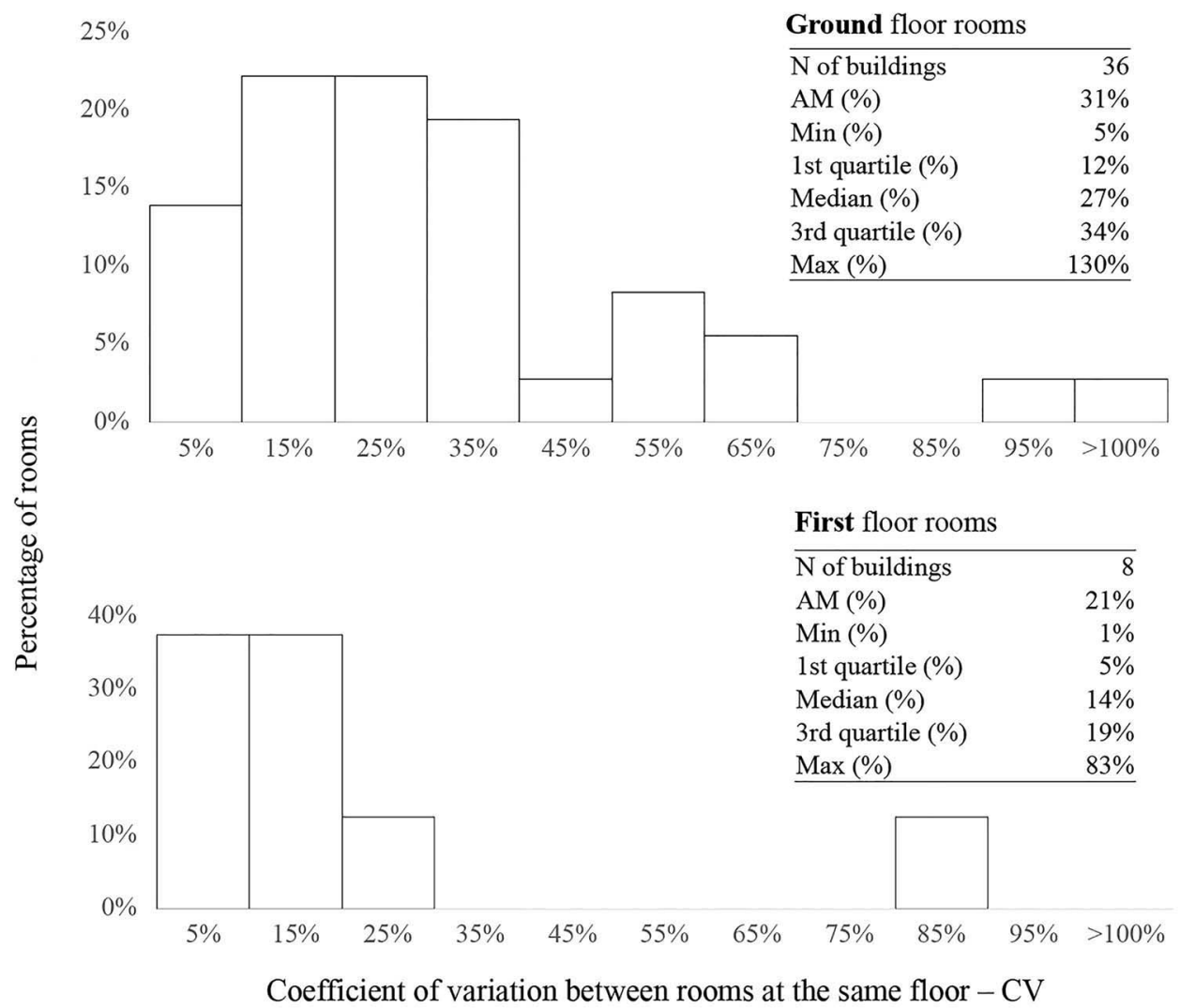

Figure 3: Room-to-room spatial variability expressed as coefficient of variations of radon concentrations measured at ground floor rooms (top) and first floor rooms (bottom).

As expected, floor level has a significant influence not only on radon level but also on radon variability ${ }^{(13)}$ : median room-to-room variability is $14 \%$ and $27 \%$, for the first floor and ground floor rooms, respectively (Figure 3). For the ground floor rooms, CV reaches also values higher than $100 \%$ : it occurs for two buildings having two floors and high average radon concentration (i.e. about 850 and 2200 $\mathrm{Bq} \mathrm{m^{-3 }}$ ).

These preliminary results suggest the need to measure all the occupied rooms at ground floor or at least a high fraction of them. Instead, data regarding first floor suggest to sample a lower fraction of rooms. Nevertheless, the relatively small sample size of this study strongly recommends further investigations in order to confirm the latter result.

\section{CONCLUSIONS}

Results from this preliminary work suggest that, for schools having only two floors (i.e. ground floor and first floor), a protocol requiring to measure radon concentrations only at ground floor may be considered adequate to assess the compliance with the reference level established by the legislation. Due to the high radon spatial variability of rooms at ground floor, measurements in a high number of rooms (preferably in all of them) are strongly recommended. Further studies are necessary to obtain more reliable estimates on spatial variability (especially for rooms at first floor) and to study the impact on spatial variability of other building characteristics such as building materials and year of construction.

\section{REFERENCES}

1. European Commission. Council directive 2013/59/ Euratom. Off. J. Eur. Union 56, 216 (2013).

2. IAEA. Radiation Protection and Safety of Radiation Sources: International Basic Safety Standards General Safety: No GSR Part 3. (IAEA Safety Standards), (Vienna: IAEA). p. 436 (2014).

3. Bucci, S., Pratesi, G., Viti, M. L., Pantani, M., Bochicchio, F. and Venoso, G. Radon in workplaces: first results 


\section{RADON SPATIAL VARIABILITY IN SCHOOLS}

of an extensive survey and comparison with radon in homes. Radiat. Prot. Dosim. 145(2-3), 202-205 (2011).

4. Bartzis, J. et al. Radon Prevention and Remediation: The RADPAR Recommendations. p. 27 (2012). Available on https://bit.ly/2s69wtC (accessed 7 January 2020).

5. IAEA. Design and Conduct of Indoor Radon Surveys. (Safety Report Series 98). (Vienna: IAEA) pp. 1-128 (2019). Available on https://bit.ly/35sx4X7 (accessed 7 January 2020).

6. Environmental Protection Agency (EPA Ireland). Protocol for the Measurement of Radon in Homes and workplaces (2016). Available on https://bit.ly/37KkqV8 (accessed 7 January 2020).

7. Health Canada. Guide for Radon Measurements in Public Buildings. (Ottawa: Health Canada) (2016).

8. Caresana, M., Ferrarini, M., Garlati, L. and Parravicini, A. Further studies on ageing and fading of CR39 PADC track detectors used as air radon concentration measurement devices. Radiat. Meas. 46(10), 1160-1167 (2011).

9. World Health Organization (WHO). WHO Handbook on Indoor Radon: A Public Health Perspective. (Geneva: WHO) (2009).

10. Demoury, C. et al. A statistical evaluation of the influence of housing characteristics and geogenic radon potential on indoor radon concentrations in France. J. Environ. Radioact. 126, 216-225 (2013).

11. Kropat, G. et al. Major influencing factors of indoor radon concentrations in Switzerland. J. Environ. Radioact. 129, 7-22 (2014).

12. Ćurguz, Z. et al. Long-term measurements of radon, thoron and their airborne progeny in 25 schools in republic of Srpska. J. Environ. Radioact. 148, 163-169 (2015).

13. Bochicchio, F. et al. Radon in indoor air of primary schools: a systematic survey to evaluate factors affecting radon concentration levels and their variability. Indoor Air 24(3), 315-326 (2014). 